\title{
Consideration Regarding Environmentally-Friendly in Manufacturing Field
}

\author{
Ikuo Tanabe \\ Nagaoka University of Technology \\ 1603-1 Kamitomioka-machi, Nagaoka, Niigata, 940-2188, Japan \\ tanabe@mech.nagaokaut.ac.jp
}

\begin{abstract}
In the 21st century, as it is important to produce products with care for protecting the earth, a producer must be careful to conserve energy, save resources and reduce waste which pollutes environment. On the other hand, in case of the manufacturing field, much lubricating oil was used for smooth drive and electrical energy of forced cooling in a machine tool was used for high accuracy and much cutting oil was also used for lubrication and cooling. This is large problem for protecting the earth. Under the present conditions in the manufacturing field, the persons concerned for design and manufacture aren't still conscious of the environmentallyfriendly. Because the several functions for checking and keeping environmentally-friendly are far from sufficient. Therefore, in this research, the calculation model for checking environmentally-friendly in the manufacturing field was proposed. And Double-ECO model technology was also proposed for promoting environmentally-friendly. At last, behaviour of a machine tool in mist of strong alkaline water using the proposed methods was investigated and evaluated. It is concluded from the results that; (1) the forced cooling using mist of strong alkaline water had a very strong influence. Thus, it could be said that the generation heat for cutting can be effectively cooled by using a mist of strong alkaline water, (2) mist of strong alkaline was eco-friendly, (3) the calculation model and the Double-ECO model technology can contribute for the environmentally-friendly in the manufacturing field.
\end{abstract}

Keywords: Forced Cooling, Machine Tool, Strong Alkaline Water, Eco-Friendly, Double-ECO Model Technology

\section{Introduction}

Since the beginning of the 21st century, the importance to manufacture products in an environmentally-conscious [1] way has been highlighted. In this regard, manufacturers not only need to conserve energy, but they also need to scrutinize in order to save resources and reduce environmentally-harmful pollutants. Nowadays, there are many researches related to the environmental impact of men [2], as well as countermeasures to reduce it [3]; however, these are still insufficient. Particularly, in the field of manufacturing, most machine tools highly depend on cutting and cooling oils to achieve the high accuracy. This represents a large environmental problem, since in most cases the cutting and cooling oils are misused, introduced into the environment and generate undesired pollution [4]. Consequently, the importance of developing new manufacturing ideas that take into account parameters such as high accuracy, high quality and a low environmental impact had been underlined. Hence, manufacturers will be in the need of daring plans, unique ideas and new technologies [5].

Therefore, even though the cutting concept of this research was "Ecology", it also included other concepts related to the industrial sector. Among these concepts are: suitable cost of a machine tool, low running cost, low maintenance fee and high precision machining. Thus, this study was meant to achieve the application of the "Ecology" and multiple industrial sector-related concepts, in conjunction with the advances of production engineering technology. For instance, regarding machine tool technology, while restraint of the thermal deformation on a machine tool was attempted to achieve high accuracy and quality, it was at the expense of using costly equipment and a large quantity of electrical energy. Even then, those the countermeasures taken were not enough to satisfy this parameters [6].

Therefore the calculation model for checking environmentally-friendly in the manufacturing field was firstly proposed. And the Double-ECO model technology was also proposed for promoting environmentally-friendly. This model is my original idea and a new concept. For the evaluation of the calculation model and the Double-ECO model technology, the cutting using CNC milling machine in the vessel with mist of strong alkaline water was finally performed for investigating the effect of water evaporation in the strong alkaline water. 


\section{Calculation Models for Checking Environmentally-Friendly and Double-ECO Model}

The calculation models for checking environmentally-friendly in the manufacturing field is firstly proposed. The primary LCA is excellent in the environmentally-friendly, however total calculation for the LAC is very difficult for the speedy developments. And that also need large cost and long time. Therefore in my research, only exhaust $\mathrm{CO}_{2}$ of the electricity and oil using the two calculation models was used for very simple LCA.

Firstly, the environmental impact of a technology will be assessed based on a comparison of the amount of exhaust $\mathrm{CO}_{2}$ by the first model. This was calculated through the relationship between the electricity consumption per hour and the $\mathrm{CO}_{2}$ emissions. For this, it was considered that the electricity used by all equipment and all working times. Furthermore, the amount of $\mathrm{CO}_{2}$ emissions, $C L_{\mathrm{CO} 2}$, is calculated by using the equation (1).

$$
C L_{C O 2}=0.468 \times W_{E}
$$

Where, $W_{E}$ is the amount of used electricity $(\mathrm{kWh})$ and 0.468 the conversion value for $\mathrm{kg}-\mathrm{CO}_{2} / \mathrm{kWh}$.

Then, subsequently, the amount of $\mathrm{CO}_{2}$ emissions due to the oil disposal was calculated by the second model. The $\mathrm{CO}_{2}$ emissions were calculated based on this value and using the equation (2) [7].

$\mathrm{CO}_{2}$ emission $\left(\mathrm{kg}-\mathrm{CO}_{2}\right)=$ Disposed oil $\mathrm{k} \ell \times$ Emitted heat energy $\mathrm{GJ} / \mathrm{k} \ell \times$ Carbon emission $\mathrm{t}-\mathrm{C} / \mathrm{TJ} \times(44 \div 12)$

Where, the emitted heat energy is $40.2 \mathrm{GJ} / \mathrm{k} \ell$ and the amount of carbon emission is $19.22 \mathrm{t}-\mathrm{C} / \mathrm{TJ}$

I think that the two calculation models should always be used for easy checking environmentally-friendly in the design and development fields.

Then the Double-ECO model technology was also proposed for promoting environmentally-friendly. The general idea for the Double-ECO technologies is explained through the following flowchart shown in Fig. 1. The first purpose of most ecology-related technologies is environmental protection, while their second purpose was the cost-profit considerations. Because of this, given the different national laws and policies, such technologies started to compromise the environment due to the cost implications. In the end, the first purpose would be neglected because of the high cost that they represent. Thus, environmentally-friendly technologies are slowly advancing.

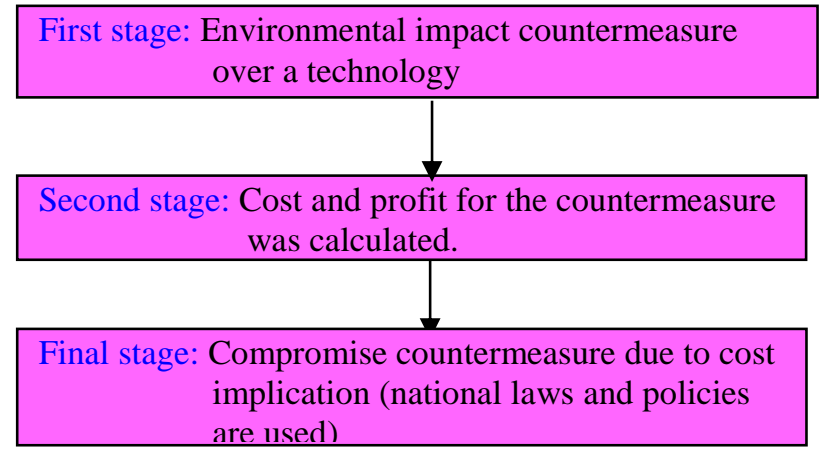

※ Final stage differs largely from the first due to compromised countermeasures

(a) Conventional environmentally-friendly technology

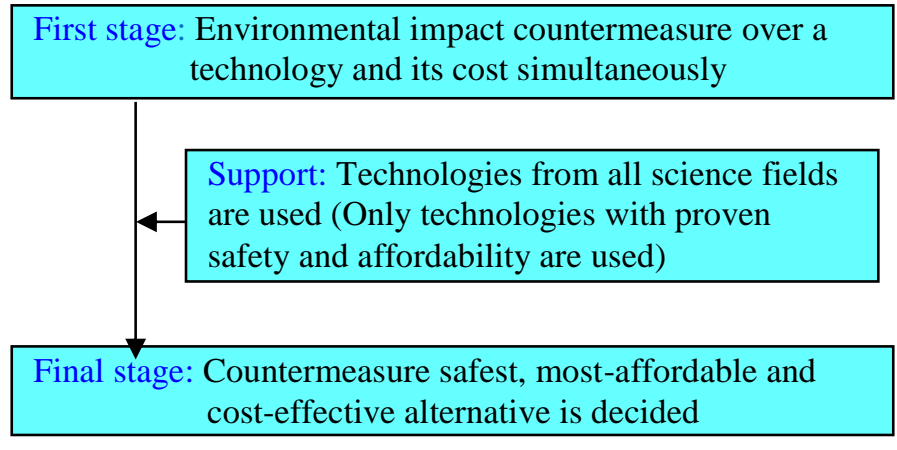

※Final stage do not differ from the first.

(b) General idea of the Double-ECO model technologies

Fig. 1: Explanation regarding the general idea of the Double-ECO model technologies with its "Ecology" and "Economy" considerations. 


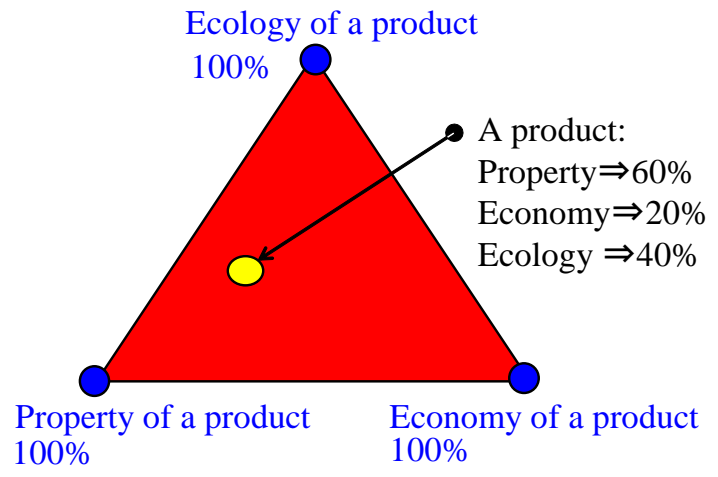

(a) Manufacturing triangle

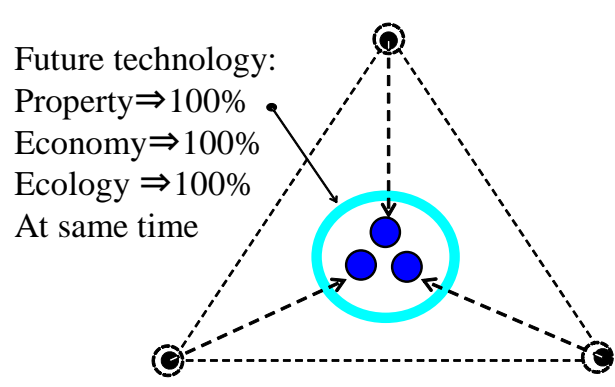

(b) Future technology using the Double-ECO model

Fig. 2: Explanation regarding the future technology using the Double-ECO model.

In contrast, the "Double-ECO model" technologies prioritizes simultaneously environment protection and cost-profit considerations so that no compromises are made at any time. Although it is very difficult to achieve this, recent environmentally-friendly technologies had made remarkable progress. The model proposed first solves the technical problems for the incorporation of such technologies as countermeasures over an existing manufacturing process, these countermeasures are selected from all the science fields available so that in the end the safest, most-affordable and costeffective alternatives can be selected. At this point, the largest profit that is feasible is guaranteed so the countermeasure itself would not be compromised. In this regard, the Double-ECO model technologies would demand an extensive knowledge of the science and economics fields for a successful development. Therefore, the Double-ECO model is coherent with the intensity of production and with the highest cost-effectiveness in eco-efficiency.

Explanation regarding the future technology using the Double-ECO model technology is shown in Fig. 2. The most products were manufactured on the one point in the manufacturing triangle with an ecology, a property and an economy points. A product is on the yellow point which has the ecology $40 \%$, the property is $60 \%$ and the economy is $40 \%$. These ecology, property and economy are often opposed clash in the manufacturing field. However, in near future, when the Double-ECO model technologies were used in the manufacturing field, the product will be on the excellent point which has the ecology $100 \%$, the property is $100 \%$ and the economy is $100 \%$ at same time. At that stage, all manufactures become naturally for environmentally-friendly.

\section{Experiment for Evaluation Regarding Calculation Models for Checking Environmentally- Friendly and Double-ECO Model}

The two calculation models for checking environmentally-friendly and the Double-ECO model technologies were evaluated in this chapter. The cutting using CNC milling machine in the vessel with mist of strong alkaline water was performed for investigating the effect of water evaporation in the strong alkaline water.

\subsection{The Corrosion Resistance of Materials in Strong Alkaline Water}

The strong alkaline water with $\mathrm{pH}$ value above 12.5 has high interfacial permeability, dissolving, emulsification, and separation properties. For these properties, it is well using for washing, sterilization, corruption prevention. Moreover, when strong alkaline water is kept long time in the air, it lost alkali property and become normal water of $\mathrm{pH}$ 7.0. This fact also regarded as very excellent for using it as cleaning agent with improved environmental protection.

In this section, the reactions of the various materials in strong alkaline water are tested. The specification of the device for making alkaline water is shown in Table 1. In the corrosion engineering, logarithmic value of metal ion concentration lesser than (-6) could not be corroded at equilibrium state. Here, according to the corrosion characteristic [8] of strong alkaline water, steel could not corrode in the alkaline water above pH10. Similarly, Nickel in the Nickel based alloys shows no chemical reaction in the range of $\mathrm{pH} 8.5 \sim \mathrm{pH} 13.0$. Moreover, titanium alloys also shows no effect under $\mathrm{pH} 13.0$ range. From these facts, it can be considered that it is possible to operate underwater metal. 
In the experiment, the tested materials are steel, titanium alloy, nickel alloy and those being used well in industries such as, copper, aluminium, brass and carbide (tool material) as shown in Table 2. These materials are put in the test tubes containing water with three $\mathrm{pH}$ values, $\mathrm{pH} 7.0, \mathrm{pH} 10.0, \mathrm{pH} 12.5$ and keep in a room with constant temperature of $20 \pm 1^{\circ} \mathrm{C}$ and $60 \%$ moisture for two months (see Table 2). The $\mathrm{pH}$ value is made to keep constant by changing alkaline water once per week. The result of the experiment regarding to alkali resistance of the materials are shown in Table 3 . The results shown there was no corrosion exhibit for the tested materials placing inside strong alkaline water for two months except aluminium. From this result, it was confirmed that the underwater cutting process for titanium alloys and nickel alloys can be applicable for compulsory tool cooling effect with the exception of aluminium. For cutting aluminium, it is necessary to take precaution and improvement as it is corroded in strong alkaline water. For the case of copper and brass, there occurred change in colour. Strong alkaline water can use for the forced cooling in the Double-ECO model technologies using the two calculation models because of high corrosion resistance (good property).

Table 1: Specification of the system for making strong alkaline water and safty of health for strong alkaline water.

\begin{tabular}{|c|c|c|c|c|}
\hline Method of generation & Closed generation type & Assist: & $t$ material & Potassium carbonate \\
\hline Value of $\mathrm{pH}$ & $\mathrm{pH} 12.5$ & \multirow{4}{*}{$\begin{array}{l}\text { Safety } \\
\text { of } \\
\text { health }\end{array}$} & Smell & Nothing \\
\hline $\begin{array}{l}\text { Quantity of } \\
\text { generation }\end{array}$ & $10 \mathrm{l} / \mathrm{h}$ & & Touch & $\Delta$ Wear gloves \& glasses \\
\hline Voltage \& Power & $100 \mathrm{~V} \& 300 \mathrm{~W}$ & & Breath & Wear mask \\
\hline Size & $495 \mathrm{~W} \times 430 \mathrm{D} \times 1100 \mathrm{H}$ & & Drink & $x$ \\
\hline
\end{tabular}

Table 2: The results of the materials tested in strong alkaline water with pH12.5 (for two month)

\begin{tabular}{|c|c|c|c|}
\hline $\begin{array}{l}\text { Work piece } \\
\text { materials }\end{array}$ & $\begin{array}{l}\text { Condition inside } \\
\text { strong alkaline water }\end{array}$ & Tool materials & $\begin{array}{l}\text { Condition inside } \\
\text { strong alkaline water }\end{array}$ \\
\hline \multirow{2}{*}{ Ti (pure) } & \multirow{2}{*}{$\circ$} & High speed tool & o \\
\hline & & Carbide(S30T,T725X) & o \\
\hline \multirow{2}{*}{ Ti6Al4V } & \multirow{2}{*}{0} & Cermet (NS530) & 0 \\
\hline & & Ceramics (LX11) & 0 \\
\hline \multirow{2}{*}{ Inconel 718} & \multirow{2}{*}{0} & CBN (KBN525) & 0 \\
\hline & & Diamond (DA2200) & 0 \\
\hline Steel (S45C) & 0 & $\begin{array}{l}\text { Coating materials of } \\
\text { tool }\end{array}$ & $\begin{array}{l}\text { Condition inside } \\
\text { strong alkaline water }\end{array}$ \\
\hline Aluminium & $x$ & TiN & 0 \\
\hline \multirow{2}{*}{\begin{tabular}{l|l} 
Copper & \\
\end{tabular}} & \multirow{2}{*}{$\begin{array}{l}\text { Changed to } \\
\text { dark brown }\end{array}$} & $\mathrm{TiC}$ & 0 \\
\hline & & DLC & 0 \\
\hline \multirow{2}{*}{ Brass } & \multirow{2}{*}{$\begin{array}{l}\text { Changed to } \\
\text { dark green }\end{array}$} & TiAlN & $x$ \\
\hline & & TiAlCr & $x$ \\
\hline
\end{tabular}

\subsection{Cooling Property for Mist with Strong Alkaline Water}

Experimental set-up is shown in Fig. 3. The nozzle consists of an air tube $(1 \times 7 \mathrm{~mm})$ and a tube $(7 \times 7 \mathrm{~mm})$ of strong alkaline water. Then cooling property for mist with strong alkaline water was measured in experiment. A sensor for measuring heat transfer coefficient and a manufactured nozzle were set in the centre of the vessel $(556 \times 386 \times 310 \mathrm{~mm})$. Sensor for measuring heat transfer coefficient is self consists of a ceramic heater $(5 \times 5 \times 1.75 \mathrm{~mm})$, two steel plates $(5 \times 5 \times 0.06 \mathrm{~mm})$ and 4 thermo-couples. The ceramic heater got caught between both two steel plates and is inputted electric power $\mathrm{E}(7.8 \mathrm{~W})$. At this time, temperature on the steel plate becomes about $100{ }^{\circ} \mathrm{C}$ in the air. Two thermo-couples are measured temperatures Tw1 and Tw2 on the centre of the each steel plate respectively. Other two thermo-couples are measured temperatures TM1 and TM2 of mist with strong alkaline water on the $5 \mathrm{~mm}$ distance from the each steel plate respectively. Heat transfer coefficient $\alpha$ is calculated by equation (3). 


$$
\alpha=\left(\frac{E / 2}{A\left(T_{\mathrm{w} 1}-T_{\mathrm{M} 1}\right)}+\frac{E / 2}{A\left(T_{\mathrm{w} 2}-T_{\mathrm{M} 2}\right)}\right) / 2
$$

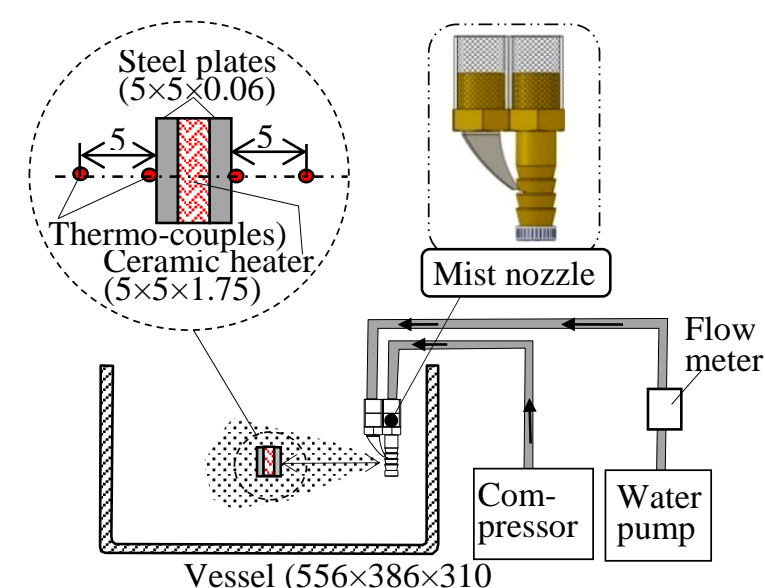

Fig.3: Experimental set-up for measuring heat transfer coefficient regarding mist of strong alkaline water.

( ) : Flow rate of strong alkaline

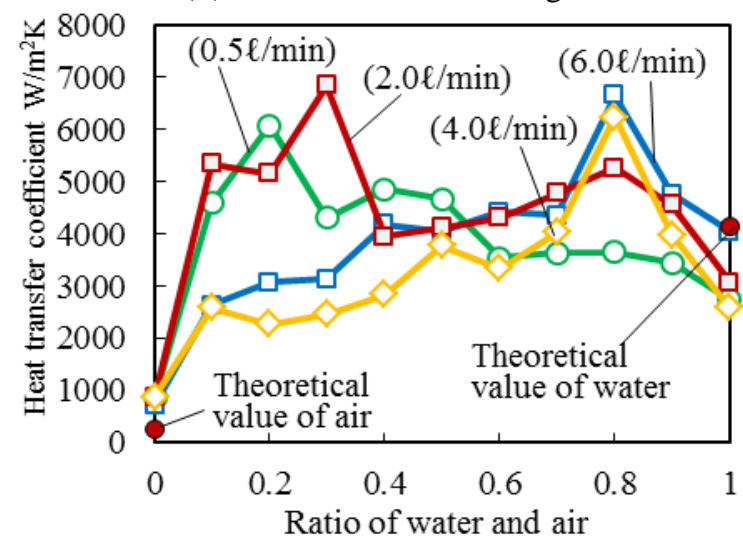

Fig. 4: Relationship between the heat transfer coefficient and the mixture ratio of air and strong alkaline water.

Where $A(5 \times 5 \mathrm{~mm})$ is area of steel plate. Average of heat transfer coefficient on twice steel plates is calculated. Because influence of radiation is also included in this heat transfer coefficient, this value is appearance heat transfer coefficient.

Furthermore, the existing relationship between the heat transfer coefficient and the mixture ratio of air and strong alkaline water is shown in Fig. 4. In this case, the length $L$ from output nozzle to measuring point was $225 \mathrm{~mm}$. Moreover, the parameter considered here is the total flow rate of strong alkaline water. There are two plots in this figure; one is the mist condition (fine strong alkaline water) which has very large forced cooling effect because of the heat of vaporization, and the other one is the fluid condition (fine air pockets) which has a very large heat transfer coefficient because it presents a high speed. These results clearly show that the forced cooling using mist of strong alkaline water has a very strong influence. Thus, it can be said that the thermal deformation of structure can be effectively cooled by using a mist of strong alkaline water. Mist with strong alkaline water can use for the forced cooling in the Double-ECO model technologies using the two calculation models because of large heat transfer coefficient (good property). 


\subsection{Cutting Property of CNC Milling Machine in Strong Alkaline Water}

The cutting fluids [9] or MQL (minimum quantity lubrication) [10] are commonly used for forced cooling during multiple processes. However, most cutting fluids pollute the environment and most MQL agents cooling performance is inferior to other cooling alternatives. Accordingly, a CNC milling machine were used for the experimentation. The effects of mist of strong alkaline water were also evaluated with respect to the tool temperature during cutting, surface roughness and the tool life parameters on a CNC milling machine [11]. In this regard, the entirety of the experimental data and further explanation about it can be consulted in a parallel research [11].

Cutting area on the CNC milling machine was filled by mist of strong alkaline water, and two tool temperatures were measured for evaluation of cooling property. Cutting conditions for tool temperature measurement are shown in Table 3. This is middle cutting. Experimental set-up is shown in Fig. 5. Amount of air is $113.3 \mathrm{l} / \mathrm{min}$, total flow rate of strong alkaline water is $0.82 \mathrm{\ell} / \mathrm{min}$ and $\mathrm{L} \mathrm{mm}$ from output nozzle to measuring point is $50 \mathrm{~mm}$. Workpiece was fixed to the spindle and tool was set to the vice on the table, because it is that the tool temperatures were measured without a hitch by thermo-couples. Then temperature on the top of the tool was estimated by the measured temperatures and FEM analysis. Here the tool model is firstly made, and tool temperatures with transient state are calculated by FEM analysis. At that time, heat transfer coefficient and heat generation on the top of the tool for input data are changed one by one. When the result of the FEM analysis became same to the result of the two measured temperature, the calculated temperature on the top of the tool is adopted for its temperature.

Temperatures on the top of the tool were shown in Fig. 6. Dry cutting and wet cutting with oil were also shown for reference. Material of the used tool is coated carbide and its optimum temperature for cutting is about $800{ }^{\circ} \mathrm{C}$.

Table 3: Cutting conditions for tool temperature measurement

\begin{tabular}{|c|c|c|}
\hline \multicolumn{3}{|c|}{ Cutting conditions } \\
\hline $\begin{array}{c}\text { Cutting speed } \\
80 \mathrm{~m} / \mathrm{min}\end{array}$ & $\begin{array}{c}\text { Feed speed } \\
0.25 \mathrm{~mm} / \mathrm{rev}\end{array}$ & $\begin{array}{c}\text { Depth of cut } \\
0.4 \mathrm{~mm}\end{array}$ \\
\hline \multicolumn{3}{|c|}{ Work piece } \\
\hline \multicolumn{3}{|c|}{ Material : S50C } \\
\hline \multicolumn{3}{|c|}{ Tool (Bite) } \\
\hline Rake angle: $5^{\circ}$ & Coated carbide \\
\hline
\end{tabular}

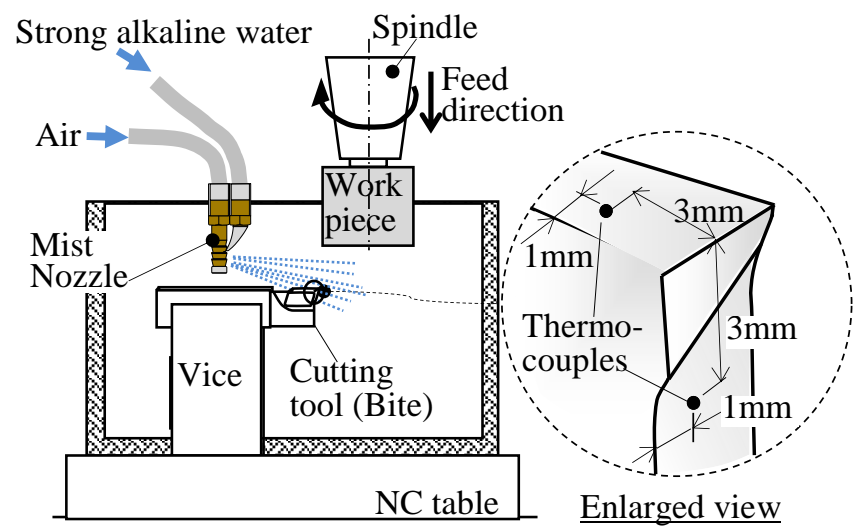

Fig. 5: Experimental setup for measurement of tool temperature. 
Temperature on the top of the tool using mist of strong alkaline water was $44 \%$ of one of dry cutting and $75 \%$ of one of wet cutting with oil respectively. Mist of strong alkaline water is effective method for cooling tool.

Tool life for evaluation of cutting using mist of strong alkaline water was performed. Cutting conditions for tool life test are shown in Table 4. This is middle cutting. Experimental set- up is shown in Fig. 7. Amount of air is $113.3 \ell / \mathrm{min}$ , total flow rate of strong alkaline water is $0.82 \ell / \mathrm{min}$ and $L \mathrm{~mm}$ from output nozzle to measuring point is $50 \mathrm{~mm}$. Dry cutting and wet cutting with oil were also performed for reference. End-mill with 2 throw away tips was used for milling machining, because it is easy and certain for judgment of limit of tool life.

Similarly, the results of the tool life test were shown in Fig.8 and dry cutting and oil wet cutting were also shown for reference. It was observed that that the tool life of the tool using mist of strong alkaline water was 2.5 times of one of dry cutting and 1.4 times of one of wet cutting with only oil respectively. Hence, it is thought that a mist of strong alkaline water is an effective method for extending the tool life during machining. To support this, in the case of the cutting using mist of strong alkaline water, defects were not observable in the microscope.

In addition, surface roughness test results are shown in Fig. 9 and dry cutting and wet cutting with only oil were also shown for reference. After machining, surface roughness on the workpiece using mist of strong alkaline at limit of tool life water was $22 \%$ of one of dry cutting and $50 \%$ times of one of wet cutting with only oil respectively. Surface roughness on the workpiece using mist of strong alkaline at start of the test is similar to that of dry cutting and wet cutting with only oil.

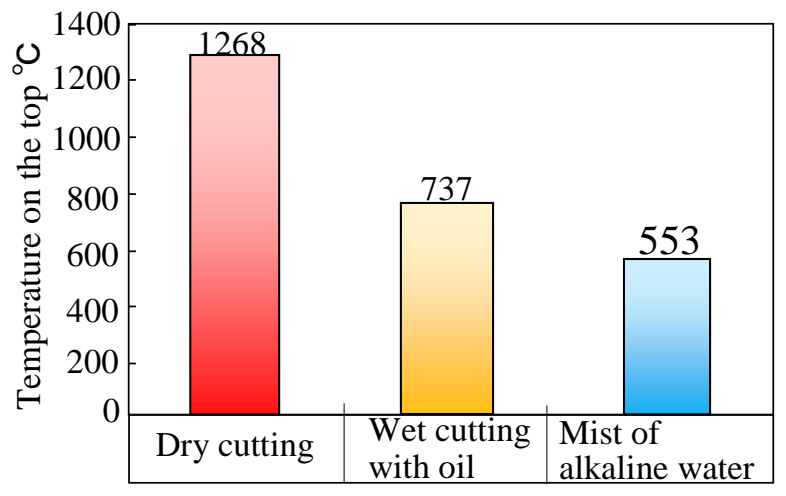

Fig. 6: Experimental results for temperature on the top.

However, a mist of strong alkaline water is thought to be an effective method for the improvement of surface roughness on the workpiece. Thus, it can be said that by using practice CNC milling machine with mist of strong alkaline water, the heat generation for cutting can be effectively removed; resulting in a low tool temperature, long tool life and fine surface roughness. Mist with strong alkaline water can use for the forced cooling in the Double-ECO model technologies using the two calculation models because of excellent cutting properties (good property).

Table 4: Cutting conditions for tool life measurement.

\begin{tabular}{|l|l|l|l|}
\hline \multicolumn{4}{|c|}{ Cutting conditions } \\
\hline $\begin{array}{l}\text { Cutting } \\
\text { speed } \\
100 \mathrm{~m} / \mathrm{min}\end{array}$ & $\begin{array}{l}\text { Feed/tooth } \\
0.15 \\
\mathrm{~mm} / \text { tooth }\end{array}$ & $\begin{array}{l}\text { Width of } \\
\text { cut } 3 \mathrm{~mm}\end{array}$ & $\begin{array}{l}\text { Depth of cut } \\
2 \mathrm{~mm}\end{array}$ \\
\hline \multicolumn{3}{|c|}{ Work piece } \\
\hline Material : S50C \\
\hline \multicolumn{2}{|c|}{ Tool (End mill with 2 throw away tips) } \\
\hline \multicolumn{2}{|c|}{ Rake angle: $5^{\circ}$} & Coated carbide \\
\hline
\end{tabular}




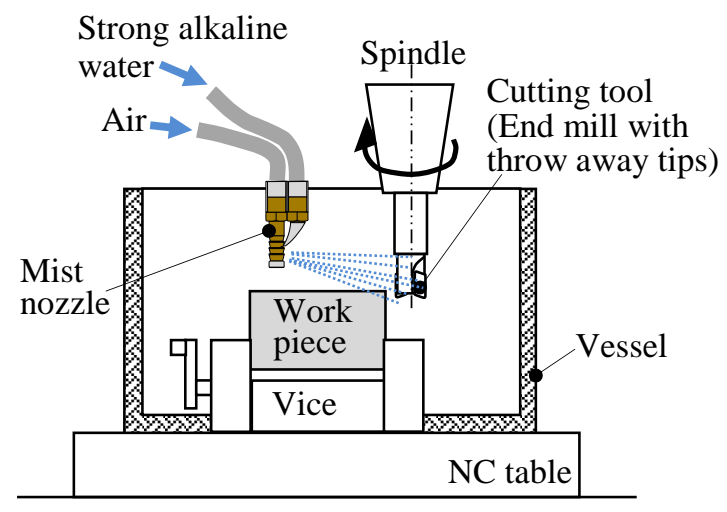

Fig. 7: Experimental set-up for measurement of tool life and surface roughness.

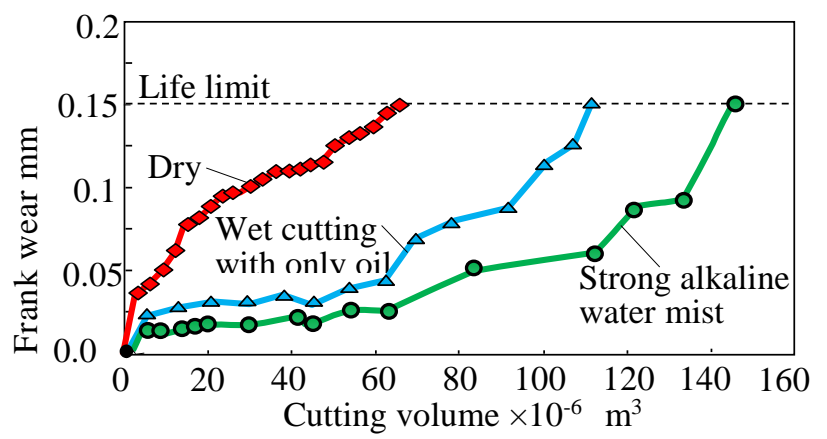

Fig. 8: Results of tool life test.

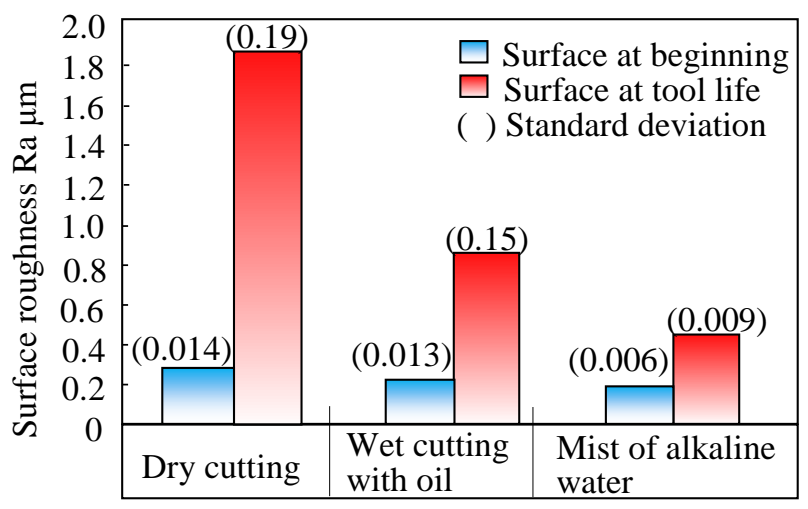

Fig. 9: Results of surface roughness.

\subsection{Evaluation and Consideration for Manufacturing in Mist of Strong Alkaline Water Using the Proposed Models}

Firstly, the environmental impact of this cooling technology will be assessed based on a comparison of the amount of exhaust $\mathrm{CO}_{2}$ using the proposed and conventional cooling. For this, it was considered that the electricity used by the coolant pump on the milling machine during conventional wet cutting was $1.2 \mathrm{~kW}$ per hour and a working year being composed of 250 days and 8-hours per day. Furthermore, the amount of $\mathrm{CO}_{2}$ emissions, $\mathrm{CL}_{\mathrm{CO} 2}$, is calculated by using the equation (2). $W_{E}$ is the amount of used electricity $(\mathrm{kWh})$ used in coolant pump and 0.468 the conversion value for $\mathrm{kg}$ $\mathrm{CO}_{2} / \mathrm{kWh}$. The corresponding calculated amount of $\mathrm{CO}_{2}$ emissions for the coolant pump is $1123.2 \mathrm{~kg}-\mathrm{CO}_{2}$. Subsequently, the amount of $\mathrm{CO}_{2}$ emissions due to the oil disposal was calculated. In this case, the amount of oil is assumed to be $340 \mathrm{~L}$ 
and disposal times to be 2 times/year a year. However, milling machines require a monthly oil fill-up which is assumed to be $30 \ell$ a month $\left(30 \ell \times 12\right.$ month=360 l). Hence, the total amount of disposed oil was assumed to be $1040 \ell$ and the $\mathrm{CO}_{2}$ emissions were calculated based on this value and using the equation (2). Where, the emitted heat energy is $40.2 \mathrm{GJ} / \mathrm{k} \ell$ and the amount of carbon emission is $19.22 \mathrm{t}-\mathrm{C} / \mathrm{TJ}$, and by using equation (2), the amount of $\mathrm{CO}_{2}$ emission due to disposed oil was calculated and a value of $2946.3 \mathrm{~kg}-\mathrm{CO}_{2}$ was obtained. Therefore, the total amount of $\mathrm{CO}_{2}$ emitted from both cases was $4069.5 \mathrm{~kg}-\mathrm{CO}_{2}$. Furthermore, the comparison between the conventional wet cutting method and the proposed method is shown in Fig. 10. In contrast, the amount of $\mathrm{CO}_{2}$ emissions of cutting in strong alkaline water mist can be reduced to $2634.9 \mathrm{~kg}-\mathrm{CO} 2, \quad(64.7 \%$ reduced $)$ in a year. This is due to the less power consumption for the cooling of the tool; as well as, the lower emissions that represent not using cutting oil in the proposed method. Thus, it can be considered that this method is not only effective in cooling the machine tool but also capable of reducing the impact to the environment.

Ultimately, a comparison between the expenses involved in the proposed cooling and the conventional cooling during machining is shown in Table 5. It can be noted that the proposal is more affordable, given that the initial costs would be considerably less because of the low market price of alkaline water. Thus, the proposed system goal of simultaneously reaching a "highly cost-effective" and "environmentally-friendly" technology is achieved.

Mist with strong alkaline water can use for the forced cooling in the Double-ECO model technologies using the two calculation models because of low cost (good economy), non-oil (nice ecology) and saving energy (nice ecology). And the two calculation models and the Double-ECO model technologies were speedy, easy and effective for checking environmentally-friendly.

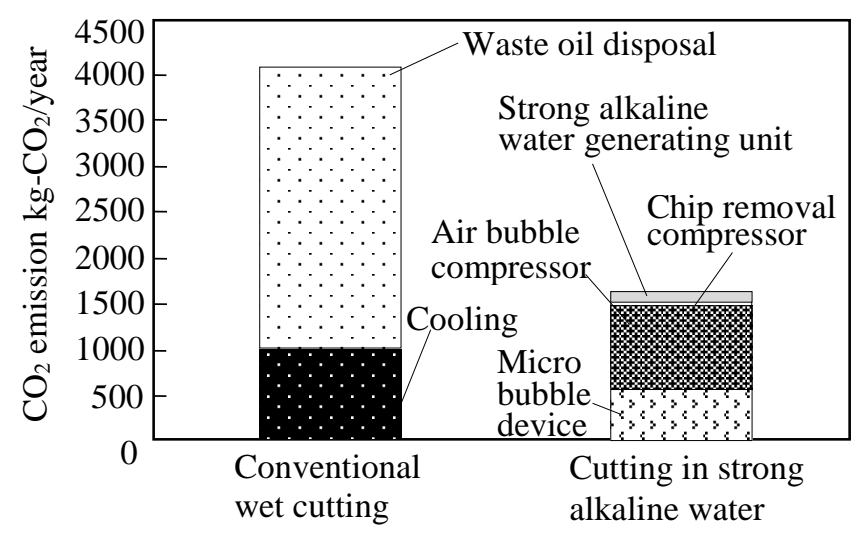

Fig. 10: Comparison of CO2 emissions (Environment).

Table 5: General overview of proposed cooling and the conventional cooling expenses (Cost-profit).

\begin{tabular}{|c|c|c|c|}
\hline Cooling method & $\begin{array}{l}\text { Proposed } \\
\text { cooling }\end{array}$ & $\begin{array}{l}\text { Convention } \\
\text { cooling }\end{array}$ & \\
\hline Cooling capacity & Very large & Average & $\Delta$ \\
\hline Initial cost & $\begin{array}{l}\text { Alkaline water } \bigcirc \\
\text { Pump }\end{array}$ & Refrig & $x$ \\
\hline Running cost & $\begin{array}{l}\text { Oil supply } \\
\text { Electricity }\end{array}$ & $\begin{array}{l}\text { Oil supply } \\
\text { Electricity }\end{array}$ & $\begin{array}{l}x \\
x\end{array}$ \\
\hline Maintenance & Little & Need & $x$ \\
\hline Remarks & $\begin{array}{l}\text { Low-environmental } \\
\text { impact and } \\
\text { profitable }\end{array}$ & $\begin{array}{l}\text { High- } \\
\text { environmental } \\
\text { impact }\end{array}$ & \\
\hline
\end{tabular}

(? : Excellent, O: Good, $\times$ :Weak 


\section{Conclusion}

From this research, the following was possible to conclude;

(1) The Double-ECO Model was proposed for the original technology regarding the environmentally-friendly. The calculation models for checking environmentally-friendly were effective for future technology.

(2) The application into real production engineering problems and technology is proposed and presented "Forced cooling using mist of strong alkaline water" researches. At that time, the Double-ECO Model is very important and effective.

(3) It was concluded from the experimental results of this technology, that improvements in the environmental pollution, mechanical properties and cost parameters were achieved through the proposed research.

\section{References}

[1] I. Tanabe and M. T. Hong, "Cutting with an environment-friendly cooling method using water evaporation," Transactions of Japan Society of Mechanical Engineers, vol. 67 no. 664, pp. 4011-4016 (in Japanese), 2001.

[2] e-Gov Japan, (2014, April 22) Ordinance related to calculation for carbon dioxide equivalent greenhouse gas emissions with their business activities of specified emitters, Article 2 (2013), [Online] Available: http://law.e-gov.go.jp/htmldata/H18/H18F15002002003.html (in Japanese).

[3] I. Tanabe, H. M. Truong and K. Yoshii, "Turning with environment-friendly cooling method using water evaporation," Transactions of the Japan Society of Mechanical Engineer, vol. 66, no. 643, pp. 1026-1030 (in Japanese), 2000.

[4] I. Tanabe and H. M. Truong "Cutting with an environment-friendly cooling method using water evaporation," Trans. of Japan Society of Mechanical Engineers, vol. 67, no. 664, pp. 4011-4016 (in Japanese), 2001.

[5] I. Tanabe, K. Yamanaka, J. Mizutani and Y. Yamada, "A new design of lathe structure for reducing thermal deformation (Design of zero-center on three directions, self-compulsory cooling and design of thermal synchronism)," Transactions of Japan Society of Mechanical Engineers, vol. 65, no. 639, pp. 4508-4513 (in Japanese), 1999.

[6] I. Tanabe, H. S. Ye, T. Iyama and Y. Abe, "Control of tool temperature using neural network for machining workpiece with low thermal conductivity," Transactions of Japan Society of Mechanical Engineers, vol. 77, no. 776, pp. 1556-1564 (in Japanese), 2011.

[7] Enviroment agency, "Law (enforce No3) for Global Warming Countermeasures in Japan-(Exhaust coefficient list)," 2006.

[8] S. Shiddaira, "Material science for corrosion and corrosion resistance," AGNE Technological Center, pp. 30-32, 255-257, 287-288 (in Japanese), 1995.

[9] S. Shintani, Hand book for cutting fluid, Kogyo Chosakai Publishing Co., Ltd., pp. 33-48 (in Japanese), 2004.

[10] M. Okada, A. Hosokawa, N. Asakawa, Y. Fujita and T. Ueda "Influence of minimum quantity lubrication on tool temperature in end milling of difficult-to-cut materials having low thermal conductivity," Transactions of Japan Society of Mechanical Engineers, vol. 78, no. 792, pp. 3093-3103 (in Japanese), 2012.

[11] I. Tanabe "Development of forced cooling using mist of strong alkaline water for restraining thermal deformation on a machine tool," MM-science journal, pp. 521-526, 2014. 